\title{
Revolutionary and Counter Revolutionary Theory in Geography and the Problem of Ghetto Formation
}

\author{
David Harvey
}

1972. Antipode 4 (2), 1-13.

How and why would we bring about a revolution in geographic thought? To gain some insight in to this question it is worth examining how revolutions and counter-revolutions occur in all branches of scientific thought. Thomas Kuhn [1962] provides an interesting analysis of this phenomenon as it occurs in the natural sciences. He suggests that most scientific activity is what he calls normal science which amounts to the investigation of all facets of a particular paradigm (a paradigm being thought of as a set of concepts, categories, relationships, and methods, which are generally accepted throughout the scientific community at a given point in time). During the process of normal science certain anomalies arise, observations or paradoxes which cannot be resolved within an existing paradigm. These anomalies increasingly become the focus of attention until science is plunged into a period of crisis in which speculative attempts are made to solve the problems posed by the anomalies. Eventually there arises out of these attempts a new set of concepts, categories, relationships, and methods, which successfully resolve the existing dilemmas as well as successfully incorporating the worthwhile aspects of the old paradigm. Thus a new paradigm is born to be followed once more by the onset of normal scientific activity [...]. Kuhn's schema is open to criticism on a number of grounds. I shall discuss two problems very briefly. Firstly, there is no explanation as to how anomalies arise and how, once they have arisen, they generate crises. This criticism can be met by distinguishing between significant and insignificant anomalies. Thus it was known for many years that the orbit of Mercury did not fit into Newton's calculations yet this

\footnotetext{
${ }^{1}$ Reprinted with permission from David Harvey and Richard Peet.
} 
anomaly was insignificant because it had no relevance when it came to the use of the Newtonian system in an everyday context. If, on the other hand, certain anomalies had arisen in, say, bridge construction, then they obviously would have been highly significant. Thus the Newtonian paradigm remained satisfactory and unchallenged until something of practical importance and relevance could not be accomplished using the Newtonian system. Secondly, there is the question, never satisfactorily answered by Kuhn, concerning the way in which a new paradigm comes to be accepted. Kuhn admits that acceptance is not a matter of logic and he therefore suggests that it involves a leap of faith. A leap of faith based of what? Underlying Kuhn's analysis is a guiding force which is never explicitly examined. This guiding force amounts to a fundamental belief in the virtues of control and manipulation of the natural environment and the leap of faith, then, is based on the belief that the new system will allow an extension of manipulability and control over some aspect of nature. Which aspect of nature? Presumably once again it will be an aspect of nature which is important in terms of everyday activity and everyday life as it exists at a particular point in history.

The central criticism of Kuhn, which these two cases point to, is his abstraction of scientific knowledge from its materialistic basis. Kuhn provides an idealist interpretation of scientific advancement when it is clear that scientific thought is fundamentally geared to material activities. This materialistic basis for the advancement of scientific knowledge has been explored by J.D. Bernal (1971). Material activity involves the manipulation of nature in the interests of [humanity] and scientific understanding cannot be interpreted independent of that general thrust. But at this juncture we are forced to add a further perspective because "the interest of [humanity]" is subject to a variety of interpretations depending upon which group of [people] we are thinking of. Bernal thus points out that the sciences in the West have, until very recently, been the preserve of a middle-class group and even recently, with the rise of what is often called the "meritocracy", the scientist is invariably drawn into middle-class ways of life and thought during the course of his career. We must thus expect the natural sciences tacitly to reflect a drive for manipulation and control over those aspects of nature which are relevant to capitalist entrepreneurs. Far more important, however, is the harnessing of scientific activity, by a process of patronage and funded research, to the special interests of those who are in control of the means of production. The coalition of industry and government heavily directs scientific activity. Thus manipulation and control mean manipulation and control in the interests of a particular group in society rather than in the interests of society as a whole (Bernal, 1971; Rose and Rose, 1969). With these perspectives we are far better able to understand the general thrust of scientific advancement hidden within the recurrent scientific revolutions which Kuhn so perceptively described.

It has frequently been questioned whether or not Kuhn's analysis could be extended to the social sciences. Kuhn appears to take the view that the social sciences are "pre-scientific" in the sense that no one social science has really established that corpus of generally accepted concepts, categories, relationships, and methods which form a paradigm. This view of the social sciences as being pre-scientific is in fact quite 
general among philosophers of science (Kuhn, op. cit. 1962, 37; Nagel, 1961). But a quick survey of the history of thought in the social sciences shows that revolutions do indeed occur and that such occurrences are marked by many of the same features which Kuhn identified in the natural sciences. There is no doubt that Adam Smith provided a paradigmatic formulation for economic thought, which was subsequently built upon by Ricardo. In modern times Keynes succeeded in doing something essentially similar. Johnson, in a recent article, explores such revolutions in thought in economics and his analysis in many respects parallels that of Kuhn's with, however, a couple of extra twists to it. At the heart of the Keynesian revolution, Johnson asserts, was a crisis generated by the failure of pre-Keynesian economics to deal with the most pressing and significant problem of the 1930's - namely, unemployment. Unemployment provided a significant anomaly. Thus Johnson suggests that:

by far the most helpful circumstance for the rapid propagation of a new and revolutionary theory is the existence of an established orthodoxy which is clearly inconsistent with the most salient facts of reality, and yet is sufficiently confident of its intellectual power to attempt to explain those facts, and in its efforts to do so exposes its incompetence in a ludicrous fashion (Johnson, 1971).

Thus objective social realities of the time overtook the conventional wisdom and served to expose its failings:

In this situation of general confusion and obvious irrelevance of orthodox economics to real problems, the way was open for a new theory that offered a convincing explanation of the nature of the problem and a set of policy prescriptions based on that explanation.

So far, the similarity to Kuhn is quite remarkable. But Johnson then adds certain new considerations some of which really stem from the sociology of science itself. He thus suggests that to be accepted a theory needs to possess five main characteristics:

First, it had to attack the central proposition of conservative orthodoxy ... with a new but academically acceptable analysis that reversed the proposition ... Second, the theory had to appear to be new, yet absorb as much as possible of the valid or at least not readily disputable components of existing orthodox theory. In this process, it helps greatly to give old concepts new and confusing names, and to emphasize as crucial analytical steps that have previously been taken as platitudinous ... Third, the new theory had to have the appropriate degree of difficulty to understand ... So that senior academic colleagues would find it neither easy nor worthwhile to study, so that they would waste their efforts on peripheral theoretical issues, and so offer themselves as easy marks for criticism and dismissal by their younger and hungrier colleagues. At the same time the new theory had to appear both difficult enough to 
challenge the intellectual interest of younger colleagues and students, but actually easy enough for them to master adequately with sufficient investment of intellectual endeavor ... Fourth, the new theory had to offer to the more gifted and less opportunistic scholars a new methodology more appealing than those currently available ... Finally, (it had to offer) an important empirical relationship ... to measure (Johnson, 1971).

The history of geographic thought in the last ten years is exactly mirrored in this analysis. The central proposition of the old geography was the qualitative and the unique and this clearly could not resist the drive in the social sciences as a whole towards tools of social manipulation and control which required an understanding of the quantitative and the general. There can be no doubt either that during the transition process old concepts were given new and confusing names and that fairly platitudinous assumptions were subject to rigorous analytical investigation. Nor can it be denied that the so-called quantitative revolution allowed the opportunity to pillory the elder statesmen in the discipline particularly whenever they ventured into issues related to the newly emerging orthodoxy. Certainly, the quantitative movement provided a challenge of appropriate difficulty and opened up the prospect for new methodologies many of which were to be quite rewarding in terms of the analytic insights they generated. Lastly, new things to measure were in abundance and in the distance decay function, the threshold and the range of a good, and the measurement of spatial pattern, we found three apparently crucial new empirical topics which we could spend an inordinate amount of time investigating. The quantitative movement can thus be interpreted partly in terms of a challenging new set of ideas to be answered, partly as a rather shabby struggle for power and status within a disciplinary framework, and partly as a response to outside pressures to come up with means for manipulation and control in what may broadly be defined as "the planning field." In case anyone misinterprets my remarks as pointing a finger at one particular group, let me say that all of us were involved in this process and that there was and is no way in which we could and can escape such involvement.

Johnson also introduces the term "counter-revolution" into his analysis. In this regard his thought is not very enlightening since he clearly has an axe to grind against the monetarists whom he designates as counter-revolutionaries even though a significant anomaly (the combination of inflation and unemployment) exists as a pressing challenge to the Keynesian orthodoxy. But there is something very important to this notion which requires analysis, for it seems intuitively plausible to think of the movement of ideas in the social sciences as a movement based on revolution and counter-revolution in contrast to the natural sciences to which such a notion does not appear to be so immediately applicable. We can analyze the phenomena of counterrevolution by using our insight into paradigm formation in the natural sciences. That paradigm formation is based on the extension of the ability to manipulate and control naturally occurring phenomena. Similarly, we can anticipate that the driving force behind paradigm formation in the social sciences is the manipulation and control of 
human activity and social phenomena in the interest of [humanity]. Immediately the question arises as to who is going to control whom, in whose interest is the controlling going to be, and if control is exercised in the interest of all, who is going to take it upon themselves to define that public interest? We are thus forced to confront directly in the social sciences what arises only indirectly in the natural sciences, namely, the social bases and implications of control and manipulation. We would be extraordinarily foolish to presuppose that these bases are equitably distributed throughout society. Our history up until the present time shows that they are usually highly concentrated within a few key groupings in society. These groups may be benevolent or exploitative with respect to other groups. This, however, is not the issue. The point is that social science formulates concepts, categories, relationships, and methods, which are not independent of the existing social relationships which exist in society. Thus the concepts used are themselves the product of the very phenomena they are designed to describe. A revolutionary theory upon which a new paradigm is based will only gain general acceptance if the nature of the social relationships embodied in the theory are actualized in the real world. A counter-revolutionary theory is one which is deliberately proposed to deal with a proposed revolutionary theory in such a manner that the threatened social changes which general acceptance of the revolutionary theory would generate are, either by cooptation or subversion, prevented from being realized.

This process of revolution and counter-revolution in social science can most explicitly be examined by studying the relationship between the political economy of Adam Smith and Ricardo on the one hand, and Karl Marx on the other. In this regard Engels, in the Preface to Volume II of Capital, provides some quite extraordinary insights. At issue, was the charge that Marx had plagiarized the theory of surplus value. Marx, however, had clearly acknowledged that both Adam Smith and Ricardo had discussed and partially understood the nature of surplus value. Thus Engels sets out to explain what was new in Marx's utterances on surplus value and how it was that Marx's theory of surplus value "struck home like a thunderbolt out of a clear sky" (Marx, 1967). ${ }^{2}$ To explain this Engels resorted to an analogy with an incident in the history of chemistry which, quite coincidentally, turns out to be one of the inspirations for Kuhn's thesis regarding the structure of revolutions in natural science (Kuhn, op. cit. 1962, 52-6). The incident concerns the relationship between Lavoisier and Priestley in the discovery of oxygen. Both ran similar experiments and produced similar results. The essential difference between them was, however, that Priestley insisted for the rest of his life in seeking to interpret his results in terms of the old phlogiston theory and he therefore called his discovery "dephlogisticated air". Lavoisier, however, recognized that his discovery could not be reconciled with the old phlogiston theory as it was and, as a consequence, was able to reconstruct the theoretical framework of chemistry on a completely new basis. Thus both Engels and

\footnotetext{
${ }^{2}$ This whole incident is discussed in depth in Althusser and Balibar (1970).
} 
Kuhn suggest that Lavoisier was the "real discoverer of oxygen vis-a-vis the others who had only produced it without knowing what they had produced."

Engels continues:

Marx stands in the same relation to his predecessors in the theory of surplus value as Lavoisier stood to Priestley ... The existence of that part of the value of products which we now call surplus-value had been ascertained long before Marx. It had also been stated with more or less precision what it consisted of ... But one did not get any further ... (all economists) remained prisoners of the economic categories as they had come down to them. Now Marx appeared on the scene. And he took a view directly opposite to that of all his predecessors. What they had regarded as a solution, he considered but a problem. He saw that he had to deal neither with dephlogisticated air nor with fireair, but with oxygen - that here it was not simply a matter of stating an economic factor of pointing out the conflict between this fact and eternal justice and morality, but of explaining a fact which was destined to revolutionize all economics, and which offered to him who knew how to use it the key to an understanding of all capitalist production. With this fact as his starting point he examined all the economic categories which he found at hand, just as Lavoisier proceeding from oxygen had examined the categories of phlogistic chemistry (Marx, op. cit. 11-18).

The Marxist theory was clearly dangerous in that it appeared to provide the key to understanding capitalist production from the point of view of those not in control of the means of production and consequently the categories, concepts, relationships, and methods which had the potential to form a paradigm were an enormous threat to the power structure of the capitalist world. The subsequent emergence of the marginal theory of value did away with much of the basics of Smith's and Ricardo's analysis (in particular the labor theory of value) and also incidentally served to turn back the Marxist challenge in economics. The counter-revolutionary cooptation of Marxist theory in Russia after Lenin's death, and the similar counter-revolutionary cooptation of much of the Marxist language into Western sociology (so much so that some sociologists suggest that "we are all Marxists now") without conveying the essence of Marxist thinking, has effectively prevented the true flowering of Marxist thought and concomitantly the emergence of that humanistic society which Marx envisaged. Both the concepts and the projected social relationships embodied in the concepts were frustrated.

Revolution and counter-revolution in thought are therefore characteristic of the social sciences in a manner which is not apparently characteristic of natural science. Revolutions in thought cannot ultimately be divorced from revolutions in practice. This may point to the conclusion that social sciences are indeed in a pre-scientific state. This conclusion is ill-founded, however, since the natural sciences have never been wrested for any length of time out of the control of a restricted interest group and 
it is this fact rather than anything inherent in the nature of natural science knowledge itself which accounts for the lack of counter-revolutions in the natural sciences. In other words the revolutions of thought that are accomplished pose no threat to the existing order since they are constructed with the requirements of that existing order broadly in mind. This is not to say that there are not some uncomfortable social problems to resolve en route, for scientific discovery is not predictable and it can therefore be the source of social tension. What this suggests however, is that the natural sciences are in a pre-social state. Thus questions of social action and social control, which the techniques of natural science frequently help to resolve, are not incorporated into natural science itself. In fact there is a certain fetishism about keeping them out since incorporating them will supposedly "bias" research conducted at the behest of the existing social order. The consequent moral dilemmas for those scientists who take their social responsibilities seriously are real indeed. Contrary to popular opinion, therefore, it seems appropriate to conclude that the philosophy of social science is in general much superior to that of natural science and that the eventual fusion of the two fields of study will not come about through attempts to "scientize" social science, but will instead require the socialization of natural science (Marx, 1964 edition, 164). ${ }^{3}$ This may mean the replacement of manipulation and control by the realization of human potential as the basic criterion for paradigm acceptance. In such an event all aspects of science will experience both revolutionary and counter-revolutionary phases of thought which will undoubtedly be associated with revolutions and counter-revolutions in social practice.

Let us return now to the initial question. How and why would we bring about a revolution in geographic thought? The quantitative revolution has run its course and diminishing marginal returns are apparently setting in as yet another piece of factorial ecology, yet another attempt to measure the distance decay effect, yet another attempt to identify the range of a good, serve to tell us less and less about anything of great relevance. In addition there are younger people now, ambitious as the quantifiers were in the early sixties, a little hungry, somewhat starved of interesting things to do. So there are murmurs of discontent with in the social structure of the discipline as the quantifiers establish a firm grip on the "production" of graduate students and on the curricula of various departments. This sociological condition within the discipline is not sufficient to justify a revolution in thought (nor should it be) but the condition is there. More important, there is a clear disparity between the sophisticated theoretical and methodological framework which we are using and our ability to say anything really meaningful about events as they unfold around us. There are too many anomalies between what we purport to explain and manipulate and what actually happens. There is an ecological problem, an urban problem, an international trade problem, and yet we seem incapable of saying anything of any depth or profundity about any of them. When we do say something it appears trite and rather ludicrous. In

\footnotetext{
${ }^{3}$ Marx clearly envisaged this kind of resolution of the conflict between the natural and social sciences.
} 
short, our paradigm is not coping well. It is ripe for overthrow. The objective social conditions demand that we say something sensible and coherent or else forever (through lack of credibility or, even worse, through the further deterioration of the objective social conditions) remain silent. It is the emerging objective social conditions and our patent inability to cope with them which essentially explains the necessity for a revolution in geographic thought.

How should we accomplish such a revolution? There are a number of paths we could take. We could, as some appear to suggest, abandon the positivist basis of the quantitative movement for an abstract idealism and hope that objective social conditions will improve of their own accord or that concepts forged through idealist modes of thought will eventually achieve enough content to facilitate the creative change of objective social conditions. It is however, a characteristic of idealism that it is forever doomed to search fruitlessly for real content. We could also reject the positivist basis of the 1960's for a phenomenological basis. This appears more attractive since it at least serves to keep us in contact with [... humanity] as a [concept] in constant sensuous interaction with the social and natural realities which surround [it]. Yet phenomenological approaches can lead us into idealism or back into naïve positivist empiricism just as easily as they can into a socially aware form of materialism. The so-called behavioral revolution in geography is pointed in all of these directions. The most fruitful strategy at this juncture is therefore to explore that area of understanding in which certain aspects of positivism, materialism, and phenomenology, overlap to provide adequate interpretations of the social reality in which we find ourselves. This overlap is most clearly explored in Marxist thought. Marx, in the Economic and Philosophic Manuscripts of 1844 and in the German Ideology gave his system of thought a powerful and appealing phenomenological basis (Marx, 1971 edition; 1964 edition). ${ }^{4}$ There are also certain things which Marxism and positivism have in common. They both have a materialist base and both resort to an analytic method. The essential difference of course is that positivism simply seeks to understand the world whereas Marxism seeks to change it. Put another way, positivism draws its categories and concepts from an existing reality with all of its defects while Marxist categories and concepts are formulated through the application of dialectical method to history as it is written here and now through events and actions. The positivist method involves for example, the application of tradition a bi-valued Aristotelian logic to test hypotheses (the null hypothesis of statistical inference is purely an Aristotelian device). Thus hypotheses are either true or false and once categorized ever remain so. The dialectic on the other hand proposes a process of understanding which allows the interpenetration of opposites, incorporates contradictions and paradoxes, and points to the processes of resolution. Insofar as it is a tall relevant to talk of truth and falsity, truth lies in the dialectical process rather than in the statements derived from the process, which can be designated "true" only at a given point in time and which in any case are contradicted by other "true" statements.

\footnotetext{
${ }^{4}$ Marx derived his phenomenological position from Hegel (1967 edition).
} 
This method allows us to invert analyses if necessary, to regard solutions as problems, to regard questions as solutions. ${ }^{5}$ I shall briefly summarize an extended argument on urban land use theory to provide an example of how the strategy described above works.

Geographers drew much of their initial inspiration from the Chicago school of sociologists (particularly Park and Burgess) who noted that cities exhibited certain regularities in spatial structure. This spatial structure was held together by some culturally derived form of social solidarity which Park called "the moral order" (Park, 1926). Engels, writing some 80 years before Park and Burgess, noted the phenomenon of concentric zoning, interpreted it in economic class terms, and identified the market mechanism operating under capitalist institutions as the generating force behind the urban structure. His description of Manchester is insightful and worth quoting:

Manchester contains, at its heart, a rather extended commercial district, perhaps half a mile long and about as broad, and consisting almost wholly of offices and warehouses. Nearly the whole district is abandoned by dwellers, and is lonely and deserted at night ... The district is cut through by certain main thoroughfares upon which the vast traffic concentrates, and in which the ground level is lined with brilliant shops. In these streets the upper floors are occupied, here and there, and there is a good deal of life upon them until late at night. With the exception of this commercial district, all Manchester proper, all Salford and Hulme ... are all unmixed working people's quarters, stretching like a girdle, averaging a mile and a half in breadth, around the commercial district. Outside, beyond this girdle, lives the upper and middle bourgeoisie, the middle bourgeoisie in regularly laid out streets in the vicinity of working quarters ... the upper bourgeoisie in remoter villas with gardens ... in free, wholesome country air, in fine, comfortable homes, passed every half or quarter hour by omnibuses going into the city. And the finest part of the arrangement is this, that the members of the money aristocracy can take the shortest road through the middle of all the labouring districts without ever seeing that they are in the midst of the grimy misery that lurks to the right and left. For the thoroughfares leading from the Exchange in all directions out of the city are lined, on both sides, with an almost unbroken series of shops, and are so kept in the hands of the middle and lower bourgeoisie ... (that) they suffice to conceal from the eyes of the wealthy men and women of strong stomachs and weak nerves the misery and grime which form the complement of their wealth ... I know very well that this hypocritical plan is more or less common to all great cities; I know, too, that the retail dealers are forced by the nature of their business to take possession of the great highways; I know

\footnotetext{
${ }^{5}$ Marx also derived his dialectical method from Hegel (see Marx, op. cit. 1964 edition).
} 
that there are more good buildings than bad ones upon such streets everywhere, and that the value of land is greater near them than in remote districts; but at the same time, I have never seen so systematic a shutting out of the working class from the thoroughfares, so tender a concealment of everything which might affront the eye and the nerves of the bourgeoisie, as in Manchester. And yet, in other respects, Manchester is less built according to plan after official regulations, is more outgrowth of accident, than any other city; and when I consider in this connection the eager assurances of the middle class, that the working class is doing famously, I cannot help feeling that the liberal manufacturers, the Big Wigs of Manchester, are not so innocent after all, in the matter of this sensitive method of construction (Engels, 1962 edition, 46-47).

The description provided by Engels can, without too much adaptation, be applied to the contemporary American city which suggests that capitalist cities tend towards a similarity of structure because the basic forces modifying them are the same. Certain passages written by Engels, for example, compare with those typically contained in contemporary governmental reports on urban problems (such as the Kerner Commission Report, 1968). It therefore seems a pity that we continue to look to Park and Burgess for inspiration (as do the Chicago geographers) instead of following up the approach adopted by Engels. In fact the tradition that most closely relates to that of Engels arises from von Thünen's analysis which has been applied by Alonso and Muth to the urban land market. In these models urban land use is determined through a process of competitive bidding for the land. Different groups in the population have different resources with which to bid and a variety of city structures can emerge depending upon the preferences of the rich groups who can always use their resources to dominate the preferences of poor groups. This is the natural outcome of models built on neo-classical marginalist principles - models which are generally regarded as Pareto optimal.

Deviations from the normative model can be taken as an indication of disequilibrium. It is generally conceded that there is considerable disequilibrium in the American city at the present time as employment has become suburbanized but poor populations have been excluded from suburban locations by a variety of devices (such as zoning). It is interesting to note that many of the policies proposed by liberal groups (planners, civil rights groups, etc) amount to advocating a return to equilibrium of the sort identified in the Alonso-Muth formulation. This is supported by large corporations who are in some cases suffering labor shortages in suburban locations. All of these proposals indicate returning to an equilibrium in which the poor still live where they can least afford to live - in other words a return to the status quo of the sort described by Engels is being advocated. How can we identify more revolutionary solutions?

Muth sought to show that the normative model he devised had empirical relevance. He tested it and found it broadly correct as a model of residential land use in 
Chicago. Let us assume the theory is true, in the sense used by logical positivists. This truth can be used to help us identify what the problem is. What for Muth would be regarded as a successful test of a theory we regard as an indicator of what the problem is. The theory predicts that the poor groups will live where they can least afford to live. Therefore, the only valid policy is to eliminate the conditions which give rise to the truth of the theory. In other words we want the von Thünen model of the urban land market to become not true. The simplest approach to this is to eliminate the mechanism which gives rise to the truth of the theory. The mechanism in this case is competitive bidding for the use of the land. If we eliminate this mechanism we will presumably eliminate the result. Competitive bidding should therefore be replaced by a socially controlled urban land market and a socialized control of the housing sector. We would thus render the von Thünen theory irrelevant to our understanding of spatial structure of cities. This process has begun in Cuba and in Havana competitive bidding has been completely eliminated as have rental payments on many dwellings (Valdes, 1971, 311$335)$.

We ought not to accept this argument too readily, for it is often the case that the mechanism which is assumed for the purpose of the theory is not necessarily the same as the real mechanisms which generate results in accord with the theory. We should merely be alerted to the possibility that the market mechanism is at fault and look for further proof of the contention. This proof can be gained from an argument stemming from the general characteristics of capitalism and market behavior. A market system becomes possible under conditions of resource scarcity for only under these conditions can price-fixing commodity exchange markets arise. The extension of market exchange has allowed an immense increase in the production of wealth. We therefore find a paradox, namely that wealth is produced under a system which relies upon scarcity for its functioning. It follows that if scarcity is eliminated then the market economy which is the source of productive wealth under capitalism is liable to collapse. Yet capitalism is always increasing its productive capacity. To resolve this dilemma many institutions and mechanisms are formed to ensure that scarcity does not disappear. In fact many institutions are geared to the maintenance of scarcity (universities being a prime example, although this is always done in the name of "quality"). A general analysis of capitalism and market exchange economies would indicate that a major barrier to the elimination of scarcity in advanced productive societies like the USA lies in the complicated set of interlocking institutions (financial, judicial, political, educational, and so on) which support the market process.

If we look very carefully we can identify manifestations of this general condition in the urban housing market. Commercial operators in the housing market (landlords, banks and other financial institutions, developers, and so on) are not interested in housing per se but are interested in maximizing their returns (rents, interest, profit - or as Marx called it, surplus value). Even if each operator behaves ethically, according to the usual norms of capitalist entrepreneurial behavior, the net output of the interactions among them all is to write of use-values in housing in one part of the city in order to reap exchange-values in another part of the city. In other 
words, scarcity is being created in one part of the city so that the market can function (at a certain level of profit) at the other end. This process can be detailed. If this process is general, and the evidence suggests that it is, then we must anticipate that the market process will naturally counteract any policies designed to eliminate scarcity in the housing market. Again, there are some disturbing similarities between the accounts provided by Engels and contemporary urban policy problems. Here is how Engels described the attempts at urban renewal in the nineteenth century:

In reality the bourgeoisie has only one method of solving the housing question after its fashion - that is to say, of solving it in such a way that the solution continually reproduces itself anew. This method is called "Haussmann" ... By "Haussman" I mean the practice which has now become general of making breaches in the working class quarters of our big towns, and particularly in areas which are centrally situated, quite apart from whether this is done from considerations of public health and for beautifying the town, or owing to the demand for big centrally situated business premises, or owing to traffic requirements, such as the laying down of railways, streets (which sometimes appear to have the strategic aim of making barricade fighting more difficult) ... No matter how different the reasons may be, the result is everywhere the same; the scandalous alleys disappear to the accompaniment of lavish self-praise from the bourgeoisie on account of the tremendous success, but they appear again immediately somewhere else and often in the immediate neighborhood! ... The breeding places of disease, the infamous holes and cellars in which the capitalist mode of production confines our workers night after night, are not abolished; they are merely shifted elsewhere! The same economic necessity which produced them in the first place, produces them in the next place also. As long as the capitalist mode of production continues to exist, it is folly to hope for an isolated solution to the housing question or of any other social question affecting the fate of the workers. The solution lies in the abolition of the capitalist mode of production and the appropriation of all the means of life and labour by the working class itself (Engels, 1935 edition, 23).

It is difficult to avoid concluding from the accumulated evidence that Engels was probably right. There is good reason to believe that the market mechanism is the culprit in a sordid drama. And yet it is curious that although all serious analysts concede the seriousness of certain of our contemporary urban problems, few call into question the forces which rule at the very heart of our economic system. We thus discuss everything except the basic characteristics of the capitalist market economy. We devise all manner of solutions except those which might challenge the continuance of that economy. Such discussions and solutions which so avoid the central issue serve only to make us look foolish, for they eventually lead us to discover, rather belatedly, what Engels was only too well aware in 1872 - that capitalist solutions provide no foundation for dealing with deteriorated social conditions which are structurally 
necessary for the perpetuation of capitalism. Such solutions are mere "dephlogisticated air." We can, if we will, discover oxygen and all that goes with it by subjecting the very basis of our capitalist society (with all its institutionalized scarcities) to a rigorous and critical examination. It is this task which a revolutionary theory must address itself to. What does this task entail?

First, let me say what it does not entail. It does not entail yet another empirical investigation of the social conditions in the ghettos. We have enough information already and it is a waste of energy and resources to spend our time on such work. In fact, mapping even more evidence of $[\ldots]$ inhumanity $[\ldots]$ is counter-revolutionary in the sense that it allows the bleeding-heart liberal to pretend he is contributing to a solution when he in fact is not. There is already enough information in congressional reports, daily newspapers, books, articles, and so on, to provide us with all the evidence we need. Our task does not lie here. Nor does it lie in what can only be termed moral masturbation of the sort which accompanies the masochistic assemblage of some huge dossier on the daily injustices to the populace of the ghetto, over which we beat our breasts, commiserate with each other, before retiring to our fireside comforts. This, too, is counter-revolutionary for it merely serves to expiate guilt without our ever being forced to face the fundamental issues let alone do anything about them. Nor is it a solution to indulge in that emotional tourism which attracts us to live and work with the poor "for a while" in the hope that we can really help them improve their lot. This, too, is counter-revolutionary, for so what if we help a community win a play-ground in one summer of work to find the school deteriorates the fall? These are the paths we should not take. They merely serve to divert s from the essential task at hand.

This immediate task is nothing more nor less than the self-conscious and aware construction of a new paradigm for social geographic thought through a deep and profound critique of our existing analytical constructs. This is what we are best equipped to do. We are academics, after all, working with the tools of the academic trade. Our task is therefore to mobilize our powers of thought to formulate concepts and categories, theories and arguments, which we can apply in the process of bringing about a humanizing social change. These concepts and categories cannot be formulated in abstraction. They must be forged realistically with respect to the events and actions as they unfold around us. Certainly, empirical evidence, the already assembled dossiers, and the experiences gained in the community can be made use of here. But all of those experiences and all of that information mean nothing unless we synthesize it into powerful patterns of thought. But our thought cannot rest merely on existing reality. It has to embrace alternatives creatively. We cannot afford to plan for the future on the basis of positivist theory for to do so would merely be to reinforce the status quo. Yet, as in the formation of any new paradigm, we must be prepared to incorporate and reassemble all that is useful and valuable with in that corpus of theory. We can restructure the formulation of existing theory in the light of possible lines of future action. We can critique existing theories as "mere apologetics" for the dominant force in our society - the capitalist market system and all its concomitant institutions. 
In this manner we will be able to establish the circumstances under which location theory can be used to create better futures and the circumstances in which it reinforces modes of thought conducive to the maintenance of the status quo. The problem in many cases is not the marginalist method per se or optimizing techniques per se, but that these methods are being applied in the wrong context. Pareto optimality as it enters location theory is a counter-revolutionary concept and so is any formulation which calls for the maximization of any one of the partial manifestations of surplus value (such as rent or return on capital investment). Yet programming solutions are clearly extremely relevant devices for understanding how resources can best be mobilized for the production of surplus value (Ellman, 1971). ${ }^{6}$ Formulations based on the achievement of equality in distribution are also counter-revolutionary unless they are derived from an understanding of how production is organized to create surplus value (Marx, op. cit. Volume 3, 876-86). ${ }^{7}$ By examining questions such as these we can at least begin to evaluate existing theory and in the process (who knows?) perhaps begin to derive the lineaments of new theory.

A revolution in scientific thought is accomplished by marshalling concepts and ideas, categories and relationships, into such a superior system of thought when judged against the realities which require explanation, that we succeed in making all opposition to that system of thought look ludicrous. Since we are, for the most part, our own worst opponents in this matter, many of us will find that a first initial step on this path will be to discomfort ourselves, to make ourselves look ludicrous to ourselves. This is not easy, particularly if we are possessed of intellectual pride. Further, the emergence of a true revolution in geographic thought is bound to be tempered by commitment to revolutionary practice. Certainly the general acceptance of revolutionary theory will depend upon the strengths and accomplishments of revolutionary practice. Here there will be many hard personal decisions to make. Decisions that require "real" as opposed to "mere liberal" commitment for it is indeed very comfortable to be a mere liberal. But if conditions are as serious as many of us believe, then increasingly we will come to recognize that nothing much can be lost by that kind of commitment and that almost everything stands to be gained should we make it and succeed.

${ }^{6}$ This experience of Russian central planning in this regard provides some interesting lessons as Kantrovich developed in programming solutions to many of the allocation distribution problems which arose in the economy (see Ellman, 1971). This suggests that some of the programming solutions to urban location problems may be more useful than not as the basis for a revolutionary urban land use theory.

${ }^{7}$ It is on this ground that I now reject my [previous] attempt to examine questions of distribution in a manner distinct from the problem of production (see Harvey, 1972). 


\section{References}

Alonso, W. 1964. Location and Land Use. Cambridge, Mass.: Harvard U.P.

Althusser, L. and E. Balibar, E. 1970. Reading Capital. London: NLB.

Bernal, J. D. 1971 edition. Science in History. Cambridge, Massachusetts: MIT Press.

Ellman, M. 1971. Soviet Planning Today. Cambridge: Cambridge University Press.

Engels, F. 1962 edition. The Condition of the Working Class in England in 1844. London: Allen and Unwin.

Engels, F. 1935 edition. The Housing Question. New York: International Publishers.

Harvey, D. 1972. Social Justice and Spatial Systems. In, Peet, R. (ed.), Geographical Perspectives on American Poverty: Antipode Monographs in Social Geography 1, 87-106.

Hegel, G. 1967 edition. The Phenomenology of Mind. New York: Harper Torchbooks.

Johnson, H, G. 1971. The Keynesian Revolution and the Monetarist Counterrevolution. American Economic Review 61 (2), 1-14.

Kerner Commission. 1968. Report of the National Advisory Commission on Civil Disorders. New York: Bantam Books.

Kuhn, T. S. 1962. The Structure of Scientific Revolutions. Chicago.

Marx, K. 1971 edition. The German Ideology. New York: International Publishers.

Marx, K. [no date] Capital, Volume 3. New York: International Publishers.

Marx, K. 1967 edition. Capital, Volume 2. Preface by F. Engels. New York: International Publishers.

Marx, K. 1964 edition. The Economic and Philosophic Manuscripts of 1844. New York: International Publishers.

Muth, R. 1969. Cities and Housing. Chicago: Chicago University Press.

Nagel, E. 1961. The Structure of Science. New York: Free Press.

Park, R. E. 1926. The Urban Community as a Spatial Pattern and a Moral Order. In, E. W. Burgess (ed.), The Urban Community. Chicago: Chicago University Press. 
Rose, H. and S. Rose. 1969. Science and Society. Harmondworth, Middx: Penguin Books.

Valdes, N. P. 1971. Health and Revolution in Cuba. Science and Society 351, 311-35. 